\title{
As CONTROVÉRSIAS RACIAIS EM OTELO DE WILLIAM SHAKESPEARE
}

\author{
Racial Controversies in Othello by \\ William Shakespeare
}

\author{
Célia Arns de Miranda*
}

If [Othello]did not begin as a play about race, then its history has made it one.

Ben Okri

Tem-se a impressão que a tragédia Otelo $^{1}$, escrita por William Shakespeare, parece estar cada vez mais vinculada aos tempos atuais. Por se tratar de um enredo que expõe temas como racismo, misoginia, miscigenação, identidade e choque culturais, conflito sexual e violência doméstica, esta tragédia escrita no início do século XVII torna-se uma misteriosa presciência do nosso mundo. As questões raciais que são expostas abertamente dentro da peça ressoam com o racismo que é vivenciado fora dela. Janet Suzman (1995, p. 279) menciona que é como se Shakespeare estivesse reproduzindo a teoria do regime de segregação racial da África do Sul quatro séculos antes que esta orientação política fosse formulada.

Em 1987, Ben Okri² (1987, apud HANKEY, 2005, p. 2) relata que ele estava sentado em um teatro londrino assistindo Ben Kingsley como Otelo e David Suchet como Iago numa produção da Royal Shakespeare

* Professora de Literaturas de Língua Inglesa na Universidade Federal do Paraná em estágio Pós-doutoral na UFSC, sob patrocínio do CNPQ de setembro de 2008 a fevereiro de 2009 ..

1 Aproximadamente, entre 1599 e 1608, Shakespeare escreveu uma série de tragédias, na seguinte provável ordem: Júlio César, Hamlet, Otelo, Rei Lear, Macbeth, Antônio e Cleópatra. Por um consenso universal, essas tragédias estabelecem o dramaturgo inglês numa posição privilegiada dentre os dramaturgos do mundo, quando não poucos críticos o colocam em primeiro lugar. As quatro tragédias, a partir de Hamlet são consideradas o auge de sua produção dramatúrgica (HONIGMANN, 2001, p. 1).

2 OKRI, Ben. Meditations on Othello, West Africa, 23 and 30 March 1987. p. 562-564; 618-619. 
Company. Ao perceber que ele era a única pessoa de pele negra na audiência, ele foi tomado por um sentimento de empatia por Otelo, outro homem negro isolado num mundo de brancos. Ele percebeu que incomoda ver Otelo como um homem negro no palco. O ressentimento de Okri está relacionado com a sua convicção de que nenhuma pessoa branca no auditório estava se sentindo da mesma forma que ele. De acordo com o seu ponto de vista, vários séculos já se passaram com Otelo assassinando Desdêmona e se suicidando no palco sem que alguma mudança significativa ocorresse em relação às pessoas negras. Ele sabe que esse fato não poderia ser diferente, ou seja, como poderiam pessoas brancas se imaginarem na 'pele' de Otelo? Logicamente, essa questão está sendo levantada por uma perspectiva política pós-colonial. A situação a que ele se refere não é pessoal ou moral, mas está ligada ao lugar que o homem negro ocupa na história: a cor de Otelo, a diferença, o fato de ele ser o outro.

Tem havido sempre muita discussão em torno da cor da pele de Otelo. Samuel Taylor Coleridge ${ }^{3}$ (1969, p. 187), por exemplo, pressupunha, equivocadamente, que Shakespeare conhecia homens negros apenas como escravos. Sabe-se que na década de 1560 , Sir John Hawkins e outros mais trouxeram um grande número de escravos da África Ocidental ${ }^{4}$ para a Inglaterra - havia tantos escravos que a rainha Elisabete I aprovou dois decretos de deportação a partir do fundamento de que eles estavam consumindo os alimentos que eram destinados ao povo inglês. Por outro lado, sabe-se, igualmente, que os contos populares de viajantes daquela época descreviam as sociedades africanas e pessoas de diferentes tipos e cores, incluindo reis, nobres, eruditos e mercadores. Por esse motivo, um homem de 'sangre azul' que também fosse negro não significaria nada de extraordinário para os ingleses, muito menos, se ele fizesse parte do enredo de um espetáculo teatral (HANKEY, 2005, p. 9-10).

Dentro desta polêmica, é relevante mencionar o fato de que para os ingleses, tanto na Idade Média quanto no período elisabetano e jaimesco, um Mouro seria sempre de cor negra. Entretanto, E. A. J. Honigmann (2001, p. 14) reitera que, independentemente do que um Mouro possa ter representado para os ingleses antes de 1600, é indispensável que se tenha

3 S. T. Coleridge proferiu uma palestra sobre a tragédia Otelo de Shakespeare na qual ele reiterou que a convenção já estabelecida de um Otelo negro é resultante do erro de confundir os epítetos usados pelos personagens como se fossem verdadeiramente descritivos. Nesse sentido, de acordo com o pensamento do poeta-crítico, o fato de Otelo ser chamado de negro, ou mesmo de beiçudo (I, i, 66) por Rodrigo, ou de bode velho e preto por Iago (I, i, 88) não quer dizer que Shakespeare tenha tido a intenção que Otelo fosse um negro genuíno (apud NEILL, 2006, p. 113).

4 As questões relacionadas com as diferenças raciais e coloniais são centrais para a compreensão da cultura do Renascimento. A novelista Michelle Cliff menciona que ela estudou o Renascimento sem se dar conta que o comércio escravo começou naquele período e que havia escravos na Europa mesmo quando Miguelângelo estava pintando o teto da Capela Sistina (apud LOOMBA, 2002, p. 1). 
em mente que Shakespeare, como todos os londrinos, tiveram a oportunidade de conviver com os mulçumanos do séquito do embaixador Mouro (representante da região costeira da Barbaria ${ }^{5}$ ) que permaneceu em Londres por um período de seis meses, a partir de agosto de 1600 . É de se esperar que este séquito, constituído por pessoas oriundas de uma cultura completamente diferente da inglesa, tanto no que se refere à aparência física quanto aos costumes, hábitos e maneira de se vestir, tenha causado um verdadeiro frisson em Londres. Inclusive, a companhia teatral, os Homens do Lorde Camerlengo, da qual Shakespeare participava, representou uma peça na corte antes da partida do embaixador (HONIGMANN, 2001, p. 2). Vale dizer que estes Mouros, oriundos região da Barbaria, eram fulvos, ou seja, de cor amarelo-tostada, em vez de serem negros (2001, p. 14). Percebese, portanto, que as primeiras audiências de Otelo tinham informações suficientes para poderem comparar o Mouro de Shakespeare, seja com os tão comentados estrangeiros (indivíduos amorenados), seja com o seu referencial histórico-cultural (indivíduos negros).

Não restam dúvidas de que Shakespeare tinha conhecimento de que nem todos os Mouros deveriam ser negros. Em Titus Andronicus, o Mouro Aaron é descrito como um Mouro negro retinto (coal-black Moor) que tem um cabelo lanoso e encaracolado (fleece and wooly hair) e um filho recém-nascido que é visto, carinhosamente, por ele como sendo um escravo beiçudo (thick lipp'd slave) ${ }^{6}$. Tendo-se essas referências em mãos, é possível afirmar que Shakespeare tenha imaginado o Mouro Aaron como uma pessoa negra. Entretanto, quando as indicações cênicas que anunciam, em $O$ mercador de Veneza, a entrada do príncipe de Marrocos, como "um Mouro fulvo, vestido todo de branco" (II, i), tem-se a prova definitiva de que Shakespeare, realmente, sabia que existem nuances na cor da pele entre os Mouros, ou seja, que aqueles oriundos do Norte da África poderiam ser fulvos, em vez de negros. A partir dessas colocações, se voltarmos a nos referir ao Otelo, não é possível relevar o fato de que esta tragédia foi escrita, provavelmente, em 1603-1604, ou seja, um curto período de tempo após o embaixador Mouro, representante da Barbaria, partir de Londres (1601). Percebe-se que existem relações entre este fato e algumas das falas em Otelo. Iago, por exemplo, ao denunciar para Brabantio a fuga de Otelo com Desdêmona, insulta o Mouro fazendo uso de uma linguagem extremamente ofensiva: "[O senhor] terá sua filha coberta por um garanhão da Barbaria;

5 O embaixador Mouro que permaneceu, por seis meses, em Londres no início do século XVII era oriundo da região costeira da Barbaria (Barbary), situada no norte da África, entre o Egito e o Atlântico; essa região é ocupada, atualmente, por Marrocos, Argel, Tunis e Trípoli.

6 As três referências que estão sendo, parcialmente, citadas acima foram retiradas, respectivamente, III, ii, 78; II, iii, 34; IV, ii, 175 (Titus Andronicus). 
terá netos que relincham, terá corcéis por primos e ginetes por consangüíneos" (I, i, 110) (SHAKESPEARE, 1999, p. 18) ${ }^{7}$. Em outro trecho da peça, fazendo uso de estratégias mesquinhas e egoístas, Iago, ao tentar convencer Rodrigo de que suas chances para conquistar o amor de Desdêmona continuavam boas, faz novamente uma referência indireta à procedência de Otelo e, consequentemente, à cor de sua pele: "Se uma cerimônia e um juramento fraco entre um bárbaro errante (an erring barbarian) e uma veneziana superrequintada não forem demais para a minha esperteza unida a todas as tribos do inferno, hás de gozá-la" (I, iii, 356; p. 44). Pode-se dizer que, a partir desses comentários, a questão acerca da cor da pele de Otelo esteja resolvida? De acordo com Honigmann (2001, p. 15), não inteiramente. Nesse caso, como poderia ser explicado o fato de que muitos personagens descrevem Otelo como beiçudo, negro e que ele próprio, na sua angústia para compreender a possível rejeição de Desdêmona, diz: "Quiçá por eu ser preto?" (III, iii; p. 101). Novamente, essas referências não elucidam a questão porque a palavra black (preto/negro) era frequentemente usada de uma maneira mais vaga para as raças não europeias, um pouco mais escuras do que muitos europeus ${ }^{8}$ (MURRAY, 1977).

Percebe-se, entretanto, que essa distinção exata entre a pele escura e a tez amorenada não é significativa, tanto que grande parte das montagens opta por representar Otelo através de uma caracterização que pode pender tanto para um negro retinto como para um norte-africano amorenado. $\mathrm{Na}$ realidade, o que importa é a percepção de que Otelo, apesar de estar, aparentemente, integrado na cultura veneziana e de ser admirado e requisitado por seus dotes na guerra, essa mesma sociedade prima por considerá-lo como o outro, aquele que pertence a uma cultura e raça diferentes, aquele que não tem o direito de conquistar uma donzela branca e requintada porque ele é o bárbaro, o diferente, aquele que, como indivíduo, é banido daquela sociedade. É, por esse motivo, que a questão da identidade cultural $^{9}$ constitui-se numa vertente prioritária nos estudos shakespearianos.

Apesar da cor da pele de Otelo ser, hoje em dia, menos controversa, o seu significado no início da cultura moderna ainda continua a sê-lo. Existe uma divergência quanto ao fato da negritude ser considerada, naquele tempo,

Todas as referências em português da tragédia Otelo, o Mouro de Veneza, escrita por Shakespeare, foram retiradas da tradução realizada por Barbara Heliodora (vide dados completos nas referências finais). Objetivando agilizar a transcrição dos trechos citados tomaremos como norma fazer referência ao ato, cena e linha(s), seguidos apenas pelo número da página da referida tradução.

8 De acordo com The Oxford English Dictionary, a palavra black era usada "loosely, to nonEuropean races, little darker than many Europeans."

9 O racismo, a xenofobia, o preconceito, dentre outros aspectos, têm gerado confrontos étnico-sócio-culturais com desdobramentos múltiplos em diferentes contextos históricos: essa abordagem pode ser flagrada em A tempestade, o mercador de Veneza, Titus Andronicus e, logicamente, em Otelo. 
uma qualidade superficial ou um indício de características internas, que não poderiam ser alteradas. Muitos críticos sugerem que a tez escura era vista como um sinal de degradação, entretanto, outros argumentam que ela começou a ser vista negativamente apenas mais tarde, como um resultado da dominação colonial dos africanos. Uma outra questão que também tem sido levantada é a de que o termo 'raça' está carregado de um significado restritivo apenas nos dias de hoje, uma vez que no Renascimento os conflitos mais pungentes entre os povos europeus cristãos e os demais, estavam, em grande parte, vinculados com a religião. Inclusive, as palavras como 'xenofobia', 'etnicismo', 'nação' foram criadas apenas mais tarde, e outras, como 'raça' e 'racismo' tinham um significado diferente do de hoje ${ }^{10}$ (LOOMBA, 2002 , p. 2). Dentro desse contexto, Honigmann (2001, p. 27) menciona que a principal fonte da tragédia Otelo, Hecatommithi (1565), escrita por Giraldi Cinthio ${ }^{11}$, deve ter despertado a atenção de Shakespeare porque este enredo que também retrata um Mouro que se casou com uma esposa branca e que, consequentemente, despertou o rancor implacável no seu alferes, permitiu Shakespeare focar um problema social que estava sendo deflagrado naquele dado momento - o racismo - ou seja, a reação dos europeus em face daquele que é considerado o outro. Sidney Kaplan é bastante enfático quando ele reitera que Shakespeare teve claramente a intenção de que Otelo chamasse a atenção para os problemas de raça. Ele menciona que Shakespeare teve um discernimento raro em relação às motivações humanas e criou este drama magnífico como um manifesto contra o racismo (BENJAMIN, 1997, p. 96). ${ }^{12}$

Na realidade, Julie Hankey (2005, p. 10) constata que o teatro já apresentou Mouros morenos ou brancos, como o Príncipe de Marrocos em o Mercador de Veneza e o Mouro de tez clara Abdilmalec em The Battle of Alcazar. Entretanto, grande parte dos Mouros que protagonizaram no palco

10 Loomba (2002, p. 3) reitera que 'raça' é uma categoria altamente maleável que, historicamente, tem se desdobrado para reforçar hierarquias sociais já existentes e para criar novas.

11 Hecatommithi, escrita por Giraldi de Cinthio, a partir da obra Decameron de Boccaccio, consiste numa coletânea de contos sobre diferentes espécies de relacionamentos amorosos. Depois de uma introdução (dez estórias), seguem-se dez séries, cada uma com dez estórias, nas quais o contador de estórias explica como maridos e esposas deveriam ser escolhidos. A terceira série escrita por Cinthio analisa, sob diversos aspectos, a infidelidade de maridos e esposas. Na sexta estória desta série, um marido descobre que suas esposa está cometendo adultério e vinga-se conspirando a sua morte 'acidental'. A sétima estória também trata da vingança de um marido (Capitão Mouro), casado com uma esposa veneziana, que é assassinada pelo suposto adultério (HONIGMANN, 2001, p. 368-370).

12 Não tem como deixar de mencionar que esse insight acurado de Shakespeare em relação ao racismo, transparece também de uma maneira evidente, em inúmeras falas, em Titus Andronicus. Quando a ama vem anunciar, com a criança em seus braços, o nascimento do filho de Tamora como o Mouro Aaron, ela faz uso de um linguajar racista referindo-se a ele como "um demo", oriundo de uma "Raça tristonha, assustadora e preta. // Eis o neném, nojento como um sapo // Entre os brancos irmãos de nosso clima” (IV, ii, linhas 66-68. SHAKESPEARE, 2003, p. 94). 
eram diabólicos e a cor da pele denunciava a sua índole. No seu ensaio, Othello and colour prejudice (Otelo e o preconceito da cor), G. K. Hunter (1978, p.41) mostra que na literatura religiosa, nos romances medievais, na tradição pictórica, mascaradas da corte e procissões, todos os demônios, os pagãos, os maus espíritos, os Mouros, os Turcos eram negros. A despeito de também haver vilões brancos, esse

fato não diminuía a força da cor escura ser vista como um símbolo. o seu significado primeiro era moral e religioso em vez de racial ou geográfico. Percebe-se que em Otelo Shakespeare subverte os estereótipos raciais de seu tempo. Apesar do general Mouro ser descrito por adjetivos bastante pejorativos como 'beiçudo', 'demo', 'lascivo mouro', 'estranho errante', 'bode velho e preto', os leitores/espectadores constatam, no decorrer da peça, que o personagem diabólico não é o Otelo negro, mas o branco Iago. É interessante observar que praticamente toda a linguagem de cunho racista é expressa pelos personagens que apresentam uma falha de caráter ou que são fracos - Rodrigo é visto como um bobo útil; Iago, como um vilão; e Brabantio, como um velho tolo. Este é mais um indício de que Shakespeare escreveu Otelo como um manifesto intencional contra o racismo. (BENJAMIN, 1997, p. 96).

Em nenhuma outra tragédia Shakespeare foi tão cuidadoso, como em Otelo, ao caracterizar o protagonista como uma pessoa nobre e respeitada. A desonestidade e a capacidade de intriga de Iago, como também o propósito do alferes em retratar Otelo da forma mais desfavorável possível, têm o poder de ressaltar, ainda mais, a alta categoria de Otelo (SHAKESPEARE, 1999, p. 7). Torna-se claro na peça que Otelo é considerado indispensável pelo governo veneziano por sua destreza e habilidade na guerra. E, também, torna-se claro, que é por esse motivo, que os venezianos o toleram, que toleram o seu casamento com Desdêmona. Tal como já foi mencionado anteriormente, há um descompasso entre o reconhecimento de Otelo como o grande general e de seu reconhecimento como um cidadão, ou seja, existe um conflito evidente na peça entre os interesses do estado e os interesses do indivíduo. Esse conflito, por sua vez, está entrelaçado com o conflito interracial e intercultural. Quando Brabantio, por exemplo, vai ao encontro de Otelo, convicto de que sua filha Desdêmona tinha sido conquistada pelo Mouro através de 'sórdidas magias', Otelo é acusado por ele de ser um estrangeiro e um negro: "Se uma jovem feliz, suave e bela, // E tão infensa às bodas que fugiu // À corte dos mais ricos dentre os nossos, // Haveria jamais (pra ser chacota) // De fugir da tutela pro negrume // De um peito como o teu, que só traz susto" (I, ii, p. 26). Shakespeare transformou o código da cor em uma das questões principais da tragédia: os múltiplos exemplos que podem ser facilmente detectados na peça denunciam uma 
quase obsessão pela exploração desse tema.$^{13}$ Entretanto, vale lembrar que Shakespeare explora em Otelo, como em todas as suas peças, uma multiplicidade de temas, o que não deixa de ser um reflexo de sua profunda compreensão da complexidade do comportamento humano.

Barbara Heliodora em seu livro Falando de Shakespeare (1997, p. 275) referenda a asserção de H. B. Charlton de que a tragédia de Otelo: 0 Mouro de Veneza "nasce do casamento de duas pessoas de origens e formações vastamente diversas", ou seja, do casamento "entre um bárbaro errante e uma veneziana super-requintada" (I, iii, p. 44), tal como as palavras zombeteiras de Iago destacam na peça. Esta tragédia, ao colocar em foco as controvérsias geradas pelo confronto entre culturas, raças, ideologias, gêneros, entre o público e o privado, entre os colonizadores e os colonizados, flagra de uma forma implícita, entretanto, contundente, o que têm caracterizado a experiência diaspórica ${ }^{14}$ da humanidade que não está mais circunscrita ao processo da aventura euroimperial desde 1492, mas que se tornou uma condição arquetípica da modernidade tardia (HALL, 2008, p. 393). Percebe-se, portanto, que a leitura de Otelo não pode se restringir a uma discussão em torno das paixões que envolvem os eternos conflitos humanos como a traição, a infidelidade, a deslealdade que acabam detonando o fim trágico do casal protagonista. Este seria o "nível explícito" de significação. Pode-se dizer que nessa peça existem dois níveis de significação: uma significação apresentada ou evidente e a significação subjacente que "deixa entrever toda uma perspectiva inexpressa do discurso" (PAVIS, 1999,

${ }^{13}$ Destacamos a seguir apenas algumas das inúmeras passagens na peça que ratificam o desenvolvimento da temática racial por Shakespeare. Percebe-se, por exemplo, que enquanto Iago vai trabalhando na sua montagem perversa para enredar Otelo, ele demonstra a sua aversão racista contra o general de todas as formas possíveis. Ele chega, inclusive, a levantar um brinde com Cássio "à saúde do negro Otelo" (II, iii, p. 65). O próprio Otelo, ao ser persuadido por Iago de que fora enganado por sua esposa, tenta desvendar os motivos que possam ter levado Desdêmona à traição, fazendo também menção à cor de sua pele: "Quiçá por ser preto, // E faltem-me as artes da conversa // Dos cortesãos, ou por estar descendo // Para o vale dos anos" (III, iii, p. 101). No decorrer da tragédia, Otelo também parece estar obcecado pela temática da cor: ele contrasta a negridão do suposto adultério de Desdêmona quando menciona que o nome de sua amada era tão claro quanto a castidade da deusa Diana, mas agora é tão negro quanto a tez de seu próprio rosto (III, iii, p. 107). Minutos antes do assassinato de Desdêmona, Otelo readquire a estatura de um herói trágico: apesar de estar à beira de um ato doloroso para ele, a sua linguagem recupera o equilíbrio que ele havia demonstrado no início da peça. Otelo, nos momentos derradeiros, não pode mais ser visto como uma pessoa que está simplesmente executando uma vingança em nome de sua honra, uma vez que ele acredita que o assassinato de Desdêmona seja um ato de justiça pública de acordo com o código de ética pagão. Nesse sentido, torna-se significativo o uso e repetição dos termos "É a causa, sim, a causa, minha'alma, // Não a nomeio ante as castas estrelas: // É a causa; mas sangue não derramo, // Nem mancho sua pele, alva de neve // [...] // (Beija-a) // Hálito quente assim quase convence // A justiça a trair-se uma vez mais" (V, ii, p. 172). Vê-se que, mais uma vez, Otelo faz menção à brancura da tez de Desdêmona cuja simples alusão de seu nome causaria uma dissonância diante da pureza e inocência das estrelas.

14 "A diáspora constitui um trauma coletivo de um povo que voluntária ou involuntariamente foi banido de sua terra e, vivendo num lugar estranho, sente-se desenraizado de sua cultura e de seu lar." (BONNICCI, 2005, p. 21) 
p. 368) ou que se expressa por certos acontecimentos ou discursos subordinados e subliminares - pelo "nível implícito" de significação (FRYE, 1992, p. 15).

Shakespeare demonstra definitivamente um grande interesse pelo charme exótico do sexo inter-racial. Torna-se curiosa a constatação de que a síndrome da atração-repulsa não se resume às relações entre Otelo e Desdêmona (Otelo), Aaron e Tamora (Titus Andronicus) e Caliban e Miranda (A tempestade), mas ela caracteriza a experiência dos negros na civilização Ocidental, inclusive quando nos reportamos às encenações dessas peças por atores negros. Ou seja, referindo-nos, especificamente, à representação do personagem Otelo por atores negros, qual tem sido a reação do público e dos críticos? A afirmação de que o papel de Otelo só foi representado por atores negros nas últimas décadas demonstra uma ignorância da brilhante carreira de Ira Aldridge. Ele foi o primeiro grande ator negro a representar Otelo e isso ocorreu na década de 1830. Entretanto, é curioso que esse ator, apesar de ser um americano nativo, nascido e educado em Nova Iorque, e que tenha sido aclamado na Grã-Bretanha e em toda a Europa, especialmente na Rússia, ele nunca pode aparecer como Otelo ou em qualquer outro papel em seu próprio país. Na Europa, por outro lado, além de representar Otelo, ele também representou papéis de personagens de tez branca ('white' roles) como Ricardo III, Hamlet, Macbeth, Lear (KAUL, 1997, p. 12). Aldridge recebeu treinamento no African Grove Theater, uma companhia formada apenas por atores negros em Greenwich Village. Shakespeare era, muitas vezes, encenado pela companhia. Entretanto, depois de serem vaiados, ridicularizados e ameaçados com violência física por objetos voadores que eram atirados por desordeiros racistas brancos que se sentiam ultrajados por negros se atreverem a representar o bardo, a companhia foi fechada e Aldridge partiu para a Europa em busca de novas oportunidades no teatro. Após estudar, por uns poucos anos, na Universidade de Edinburgh (Escócia), ele iniciou a sua carreira nos palcos ingleses. Pouco tempo depois, ele já estava sendo aclamado como o mais requintado Otelo do século XIX (BENJAMIN, 1997, p. 99). No período de 1831-32, Aldridge alcançou um grande sucesso em Dublin (Teatre Royal): um ator negro 'naturalmente' representando Otelo - e, na realidade, dando uma ênfase à sua negritude em diversas cenas durante a representação - parece ter impressionado a audiência de imediato como um evento teatral bastante significativo. Tal fato foi exaltado como sendo a novidade mais singular no Teatro do Mundo, isto é, um "ator de cor" (MARSHALL; STOCK ${ }^{15}$

${ }^{15}$ MARSHALL, Herbert; STOCK, Mildred. Ira Aldridge: the negro tragedian. London: Oxford 
1958, apud KAUL, 1997, p. 12). Por volta de 1850, Aldridge tinha amadurecido de tal maneira no papel e alcançado uma perfeição artística tão grande que um crítico em Viena declarou que o próprio Shakespeare não teria sonhado para Otelo uma interpretação tão perfeita. É interessante observar que no dia 03 de janeiro de 1853, enquanto Aldridge dava início a uma temporada na Casa de ópera Italiana (Italian Opera House) em Berlin como Otelo, os Estados Unidos estavam debatendo acaloradamente a escravidão que estava levando o país a uma sangrenta guerra civil (1861-1865).

O alto nível de representação que havia sido estabelecido por Aldridge no século XIX teve continuidade com a atuação de Paul Robeson no século XX. Robeson foi um verdadeiro homem afro-americano da Renascença: além de ter sido um atleta de projeção e um pesquisador, ele representou um Otelo cuja atuação foi marcante. Com atributos físicos pelos quais foi celebrado (alto, estrutura bem constituída), ele também era considerado muito inteligente, graduou-se em Direito, cantava em vinte e quatro línguas, tinha uma voz de baixo, melodiosa e educada, que lhe rendeu um tom profundo e grave no palco. Em 1930, quando ele se apresentou pela primeira vez como Otelo nos palcos britânicos, quase um século depois de Aldridge, a atriz que contracenou com ele como Desdêmona, foi a britânica Peggy Ashcroft. Apesar de estar recentemente casada, ela se apaixonou perdidamente por Robeson, que também era casado. Tem como afirmar que "qualquer semelhança com o enredo é mera coincidência"? Tendo esse exemplo real em mãos, não há como não nos referirmos à controvérsia levantada por Oscar Wilde quando ele propôs a inversão do conceito aristotélico de realidade artística - "a arte imita a vida" ou é "a vida que imita a arte" ${ }^{16}$ ? Cinquenta anos mais tarde, Ashcroft confessou que o que aconteceu com ela e Paul foi inevitável. E, ela ainda acrescentou, "Como poderia alguém não se apaixonar naquela situação e por aquele homem"? ${ }^{17}$ (BENJAMIN, 1997, p. 101)

Depois do sucesso de público e de crítica nos palcos ingleses, surgiu uma conversa sobre a possibilidade da produção ser levada para os Estados Unidos em 1931. Robeson falou para o New York Times que ele não

16 Oscar Wilde (1854-1900) em seu ensaio The decay of lying menciona como um de seus preceitos básicos que "a Vida imita a Arte muito mais do que a Arte imita a Vida". Essa teoria que não havia sido ainda formulada tornou-se extremamente prolífera e lançou uma nova luz sobre a história da arte. Wilde considerava o movimento realista um suicídio literário, uma arte estéril, um fracasso total: as duas coisas que, no seu entender, um artista deveria evitar eram a modernidade da forma e a modernidade do conteúdo. Vale lembrar que quando Wilde se refere à modernidade ele, na realidade, está fazendo uma alusão ao Realismo que era o movimento literário em ascensão naquele dado momento. (WILDE, 1994. p. 51)

${ }^{17}$ As palavras faladas por Peggy Ashcroft em relação à sua paixão por Robeson são: "How could one not fall in love in such a situation with such a man?" 
se importaria de representar aquelas cenas em algumas partes dos Estados Unidos. Entretanto, a audiência se tornaria ríspida; na realidade, ele considerava que essa empreitada seria muito perigosa. No ambiente racista de seu tempo, Robeson sempre teve muita prudência ao contracenar cenas românticas com uma atriz branca no palco, mesmo na Inglaterra. Apesar das críticas continuarem muito positivas na Inglaterra, Robeson mantinha o seu ceticismo quanto à reação das audiências americanas de cor branca, particularmente, do sexo masculino, ao testemunharem um herói Mouro cortejando uma bonita atriz branca. Provavelmente, esse é o motivo que impediu muitos diretores de escalarem atrizes como Avery Brooks e Meryl Streep, ou outras atrizes, comparavelmente talentosas, para comporem pares românticos como Otelo e Desdêmona, ou Aaron e Tamora. Finalmente, em 1943, doze anos depois de sua estreia em Londres, Robeson teve a sua chance para representar Otelo na sua terra natal. A crítica foi extremamente favorável: Burton Rascoe mencionou que ele nunca em sua vida tinha visto uma audiência tão quieta, tão tensa, tão fascinada com o que estava acontecendo. $\mathrm{O}$ impacto, como muitos críticos salientaram foi pelo fato de um ator negro estar representando o papel principal. o crítico da Variety resumiu a reação geral quando declarou que depois da atuação de Robeson, nenhum ator branco deveria ousar representar Otelo (BENJAMIN, 1997, p. 102).

Os comentários, tanto por críticos europeus quanto americanos, refletem uma questão central. A tensão dramática em Otelo não se limita ao fato de um homem negro poderoso e uma mulher branca bonita estarem juntos no palco como amantes, mas está também vinculada ao fato de atores negros relacionarem-se emocionalmente com o papel de tal forma que seria inatingível para os atores brancos ${ }^{18}$. Tal como o solitário personagem negro na peça, a situação do ator negro no elenco aproxima-se com a situação de Otelo na sociedade veneziana. E, devido à persistência, de maneira geral, do racismo no mundo, o ator negro numa noite de estreia sente a mesma ambivalência e hostilidade, real ou imaginada, que Otelo experimentou em Veneza. Além desses fatores, atores negros mantêm uma relação muito próxima com os Mouros shakespearianos que, como eles, estão tentando negociar o seu espaço dentro de uma sociedade hostil branca. Robeson exemplifica dizendo que ao interpretar o papel de Otelo, ele sempre ouvia, cuidadosamente, o que os diretores e as autoridades shakespearianas tinham

18 Sidney Kaplan teve a oportunidade de assistir tanto Robeson quanto Olivier representando o personagem Otelo. Ele observa que a representação de Robeson provê o melhor argumento da razão pela qual mesmo o melhor dos atores brancos não poder representar este papel. Esse fato torna-se especialmente óbvio quando comparado à representação de Laurence Olivier que, de acordo com Kaplan, foi horrível. A única maneira que Olivier poderia conceituar o personagem seria como um louco (BENJAMIN, 1997, p. 104). 
a lhe dizer, entretanto, em muitos casos, o Otelo deles não pensava e nem agia e reagia como ele imaginava que um grande soldado negro deveria fazer e, nesses casos, ele representava de acordo com o seu modo de ver. (BENJAMIN, 1977, p. 103).

O teatro shakespeariano, muito apropriadamente chamado 'O Globo' (The Globe), exerceu uma enorme influência na formação da opinião pública dos ingleses sobre o mundo. Por volta de 1600 , em torno de 18.000 a 20.000 espectadores foram aos teatros londrinos a cada semana, o que fundamenta o fato de que os ingleses formaram a imagem do que o mundo estrangeiro representava a partir do que lhes era passado pelo palco e não através dos livros ou por interações com a vida real (LOOMBA, 2002, p. 7-8). Pode-se afirmar que as peças de Shakespeare têm sido, desde então, um instrumento poderoso entre gerações e culturas, ou seja, um meio para transmitir e moldar ideias, inclusive, sobre as questões relacionadas ao colonialismo e raça. Entretanto, acrescente-se o fato de que, apesar de Shakespeare exercer uma ascendência sobre as concepções vindouras, as respostas dos leitores/ espectadores ao conteúdo de suas peças estão intimamente ligadas às tensões raciais experimentadas por eles em seus próprios contextos. E é de se esperar que essas visões e experiências sejam, não poucas vezes, diametralmente divergentes. Para Octavio Mannoni (1990), por exemplo, a inferioridade de Caliban em relação à Próspero, em $A$ tempestade de William Shakespeare, confirma que há uma desigualdade natural entre os seres humanos, fato que justifica o colonialismo. Por outro lado, Aimé Césaire (2000) menciona que a peça denuncia as misérias da opressão colonial. Peças teatrais como Otelo e A tempestade expõem problemas raciais para uma audiência cujas vidas têm sido e continuam a ser enormemente afetadas pela questão racial. Ania Loomba (2002, p. 5) menciona que é tão necessário confrontar as mais diversas e longas histórias sobre raça quanto é necessário mostrar que o pensamento racial tem uma história que não é nem fixa e nem universal.

\section{RESUMO}

A tragédia Otelo, o Mouro de Veneza, ao colocar em foco as controvérsias geradas pelo confronto entre culturas, raças, ideologias, gêneros, entre o público e o privado, entre os colonizadores e os colonizados, evidencia de uma forma contundente o que tem caracterizado a experiência diaspórica da humanidade, fato que não está mais circunscrito ao processo da aventura euro-imperial desde 1492, mas que se tornou uma condição arquetípica da modernidade. As questões raciais que são flagradas dentro da peça ressoam com o racismo que é vivenciado fora dela. Pergunta-se: Qual é o lugar que um 
homem negro ocupa na história? É por esse prisma que o estudo dessa tragédia não pode prescindir de uma abordagem da crítica pós-colonialista que se debruça sobre a análise da relação entre o discurso e o poder.

Palavras-chave: William Shakespeare; Otelo; Pós-colonialismo.

\begin{abstract}
When the tragedy, Othello, the Moor of Venice, puts forward into discussion the controversies which are generated by the conflicts between: cultures; races; ideologies; genres; the State and the individual; the colonizers and the colonized, it demonstrates emphatically what has characterized the diasporic experience of humanity. This fact does not only describe a process of the euro-imperial venture since 1492 , but it becomes the archetypal condition of modernity. The racial questions which are evidenced in the play reflect the racism which is all too present in real life. We must ask ourselves: what place does the negro occupy in history? It is from this perspective that the study of this tragedy must not shy away from being an approach to the post colonialist theory which debates the relationship between discourse and power. Key-words: William Shakespeare; Othello; Post colonialism.
\end{abstract}

\title{
REFERÊNCIAS
}

BENJAMIN, Playthell. Did Shakespeare intend Othello to be black? A meditation on blacks and the bard. IN: KAUL, Mythili. (Ed.). Othello: new essays by black writers. Washington D.C.: Howard University Press, 1997.

BONNICCI, Thomas. Conceitos-chave da teoria pós-colonial. Maringá: UEM, 2005.

CÉSAIRE, Aimé. Discourse on colonialism. Trad. Joan Pinkham. New York: Monthly Review, 2000.

CHARLTON, H. B. Shakespearian Tragedy. Cambridge, 1952.

COLERIDGE, Samuel. Taylor. IN: HAWKES, Terence. (Ed.). Coleridge on Shakespeare. Harmondsworth: Penguin, 1969.

FRYE, Northrop. Sobre Shakespeare. Org. Robert Sandler; Trad. Simone Lopes de Mello. São Paulo: Universidade de São Paulo, 1992. (Criação \& Crítica, 9).

HALL, Stuart. Da diáspora: identidades e mediações culturais. 2.ed. Org.: Liv Sovik. Tradução: Adelaine La Guardia Resende et al. Belo Horizonte: UFMG, 2008. 
HANKEY, Julie. (Ed.) Othello. 2 ed. Cambridge: Cambridge University Press, 2005.

HELIODORA, Barbara. Falando de Shakespeare. São Paulo: Perspectiva; Estudos: 155. Rio de Janeiro: Funarte: Cultura Inglesa, 1997. (Estudos, 155)

HONIGMANN, E. A. J. (Ed.). Othello. 3 ed. London: The Arden Shakespeare, 2001.

HUNTER, G. K. Othello and colour prejudice. In: Dramatic identities and cultural transition: studies in Shakespeare and his contemporaries. Liverpool: Liverpool University Press, 1978.

KAUL, Mythili. (Ed.). Othello: new essays by black writers. Washington D.C.: Howard University Press, 1997.

KOTT, J. Shakespeare nosso contemporâneo. Tradução: Paulo Neves. São Paulo: Cosac \& Naify: 2003.

LOOMBA, Ania. Shakespeare, race, and colonialism. Oxford: Oxford University Press, 2002.

MAIA, Reinaldo. Otelo: o poder do discurso, o discurso do poder. In: MAIA, Reinaldo; RODRIGUES, Marco. A. Caderno do Folias: Otelo. 4.e 5 ed. São Paulo: Folias d'Arte Produções Artísticas; primeiro semestre 2003.

MANNONI, Octave. Prospero and Caliban: the psychology of colonialism. Ann Arbor: Ann Arbor Paperbacks, 1990.

MURRAY, James. A. H. et al. (Ed.). The Oxford English Dictionary. v. 13; 1977.

NEILL, Michael (Ed.). William Shakespeare: Othello, the Moor of Venice. Oxford: Oxford University Press, 2006.

PAVIS, Patrice. Dicionário de Teatro. Tradução: J. Guinsburg e $M^{\mathrm{a}}$ Lúcia Pereira. São Paulo: Perspectiva, 1999.

SHAKESPEARE, William. Otelo, o mouro de Veneza. Tradução: Barbara Heliodora. Rio de Janeiro: Lacerda, 1999.

Titus Andronicus. (Trad.) Barbara Heliodora. Rio de Janeiro: Lacerda, 2003.

SUZMAN, Janet. Who needs parables? Tanner Lectures on Human Values, 1995. Disponível em: <www.tannerlectures.utah.edu/lectures/suzman96.pdf> Acesso em: 18 de outubro de 2008.

WILDE, Oscar. A decadência da mentira e outros ensaios. Tradução: João do Rio. 2 ed. Rio de Janeiro: Imago, 1994. 
